\title{
Utilization of Health Care Services of Young Married Women for Health Problems during Pregnancy Period in Thiruvarur District, Tamilnadu, India
}

\author{
Dr. P. R. Rejoice, \\ Consultant, Kottayam, Kerala, India
}

\begin{abstract}
The aim of this study was to assess the utilization of health care services of young married scheduled castes women for health problems during pregnancy period in Thiruvarur district, TamilNadu, India. Multistage stratified random sampling technique was applied to select 605 women in the age group of 15-24 years in the five blocks of Thiruvarur district during July 2010 - April 2011. The result reveals that 58.2\% of the scheduled castes women were experienced health problems during their pregnancy period. Around $67 \%$ women were sought treatment for pregnancy related health problems. The women who completed higher secondary and above education received treatment for the health problems during pregnancy (80\%), whereas this proportion for illiterates was only $52 \%$. The women in households in the highest wealth quintile were more likely to receive treatment for their pregnancy related health problems $(80 \%)$ than women in households in the lowest wealth quintile (55.2\%). It concludes that women in the study area were living with very poor standard of health because of less educated, unemployment, inadequate health care centers. They are the victims of not only reproductive health problems but other communicable diseases also. It is important that state government should be strengthening the health activities to reduce the reproductive health problems among deprived population.
\end{abstract}

Keywords: Pregnancy related health problems, scheduled castes, standard of living index, young married women.

\section{Introduction}

Worldwide, almost 536,000 women died in 2005 from pregnancy related complications, majority of them were from developing countries. More than half of the maternal deaths $(270,000)$ occurred in the SubSaharan Africa region alone, followed by South Asia $(188,000)$. Thus, Sub-Saharan Africa and South Asia accounted for $86 \%$ of global maternal deaths [1]. Around one fifth of the births worldwide and one fourth of maternal deaths are occurring in India [2]. Maternal mortality as well as life risk of maternal death in central India is well above the national average. The risk of death associated with pregnancy complications and delivery is relatively high in central India. This shows that central India shares the maximum burden of reproduction related morbidity and mortality of women. This problem arises not only from economic but also social and cultural factors as well as inadequate and under utilization of health services [3].

Maternal and child health care is one of the eight basic components of primary health care in declaration of Alma Ata. The International Conference on Population and Development [4] also reiterated the importance of women's health, and reproductive and sexual health for overall development. Pregnancy is one of the important events in a woman's life, but many times it can become dangerous to her life, in India and other developing countries, due to the lack of medical care and ignorance.

Social and medical causes are associated with pregnancy complications such as delay in decisions to seek care, delay in accessing and receiving care. Other social causes such as inequality in providing proper nutrition, education, and medical treatment may affect women's health. Malnutrition, infection, early and repeated child bearing and high fertility have an adverse impact on the maternal health condition. Lack of access to health care along with poor quality of the delivery system and its responsiveness to women's needs make women more vulnerable to maternal morbidity. In general, maternal and reproductive morbidity is an outcome of not just biological factors, but also of women's poverty, powerlessness and lack of control over the resources as well [2]. Lack of education and low economic status emerged as significant factors affecting women's health [5]. Poor health management, lack of primary health care facilities and logistic difficulties within the referral process further complicated the problem. The study points to the need for proper health intervention, increasing access to emergency obstetric care and effective health management to assure a reduction in maternal deaths. 


\section{Characteristic features of Scheduled Castes in India}

The Indian caste system is a highly complex institution, though social institutions resembling caste in one respect or another are not difficult to find elsewhere, but caste is an exclusively Indian phenomenon. The "Scheduled Castes" is the legal and constitutional name collectively given to the groups which have traditionally occupied the lowest status in Indian society and the Hindu religion which provides the religious and ideological basis for a "disadvantaged" group, which was outside the caste system and inferior to all other castes [6]. At presents, the scheduled castes in India constitute around $16.8 \%$ of the total population. Almost one-third of them live below poverty line and do not have access even to the basic needs like food, clothing, and shelter and constitute major part of our labour force and are generally engaged in petty occupations like agriculture labour, construction work, hawking and other low grade jobs [7]. There is a general consensus that the health status of the scheduled castes population is very poor and worst [8].

\section{Data \& Methodology}

Objective: The aim of this study was to assess the utilization of health care services of young married scheduled castes women for health problems during pregnancy period in Thiruvarur district, TamilNadu, India.

\section{Selection of the District}

According to 2001 census, Thiruvarur district was the highest vulnerable group or Scheduled Castes populated district and also backward district in TamilNadu state.

\section{Selection of the Taluks}

Multistage stratified random sampling technique was applied to select the respondents from the Thiruvarur district for the research purpose in the period of ten months from July 2010 to April 2011. Selection of the taluk was the first step in the multistage stratified sampling techniques. Thiruvarur district had totally seven Taluks, which comprise 573 revenue villages and 430 panchayat villages. In the first stage, out of seven taluks, it was decided to select five taluks. These five taluks represent the geographical area of the study district.

\section{Selection of the Sample Blocks}

In the second stage, the purposive sampling technique was applied to select the blocks, for the convenience of research work. The selected blocks were Nannilam, Thiruvarur, Tiruturaipundi, Valangaiman, and Mannargudi.

\section{Selection of the Sample Villages}

The selected five blocks totally comprise 352 revenue villages. During the third phase, an attempt was made to find out the villages which had more than $50 \%$ of scheduled castes population. The total number of these villages was 87 . Out of the 87 villages, around one-third of the villages were selected from each of the blocks by lottery method. The total number of selected villages was 28 .

\section{Selection of the Sample Respondents}

After identifying the villages in each block, house listing operation was carried out in each of the selected villages prior to the data collection to provide the necessary frame for selecting the households for the study. Totally 6376 houses were listed in all the five blocks. Identification of eligible married young women (15-24 years) in each household was the next step in the research. There were 1164 households with the target population (39 households had two couples). Totally 1203 women in the age group of 15-24 were identified in all the five blocks. These women were living with their husbands and had given at least one birth before one year prior to the survey.

It was planned to select half of the population in each of the sample villages i.e., 601 was fixed as the sample size of the study. Thus, in all, 661 respondents were selected following circular systematic random sampling technique. Of these 661, 605 respondents were completely participated for the research study (response rate was 91.5\%).

\section{Results \& Discussion}

All the respondents were asked whether they had experienced any health problems and also they had received any kind of treatment for those health problems during their pregnancy period and the results are tabulated. The result shows (Table 1) that more than half of the scheduled castes women experienced health problem during their pregnancy period $(58.2 \%)$. With regard to prevalence of specific pregnancy-related health problem, the nauseas and vomiting were most commonly reported by the SC women (30.7\%) and followed by abdominal pain $(26.7 \%)$. Maternal age affects the frequency of complications during pregnancy and childbirth. This is so because the woman's age may be related to her attitude about health care provisions. Young women 
who become pregnant are often at risk of obstructed labour if they have not yet grown to their full height or pelvic size. Obstructed labour causes death when adequate emergency obstetric care is unavailable. Also young women are more likely to suffer from eclampsia, which can be life-threatening to mother and baby. Pregnancies at older ages are not free from complications. The health risks of childbearing are increases after age 39 [9].

As mentioned in the patriarchal Indian society women bear the major burden of the household chores and it is not compensated with balanced diet. Even during pregnancy, she is not given any concession from the household work and there is hardly any improvement in her diet. Thus, in most of the cases, she is malnourished and is overexerted, which worsens her condition during pregnancy [10]. Among the study population around one-fifth of women had convulsion that was not from fever (20.2\%) and another $19 \%$ experienced swelling of hand, legs or face. Further, excessive bleeding does not seem to be a common problem among these women as it was reported by only $9.4 \%$. It is also noticed from the (Table 1) that an insignificant proportion of women experienced low blood pressure (8.8\%) and high blood pressure (3.4\%). In India, every year a large number of women suffer obstetric problems. According to NFHS-3, six percent women were suffering from poor vision, nine percent had night blindness, $10 \%$ reported convulsion, $25 \%$ had swelling in legs, body or face, $48 \%$ had excessive fatigue and four percent had vaginal bleeding during pregnancy [11].

\section{Binary logistic regression examining the effect of background characteristics on health problems during pregnancy period}

Binary logistic regression technique has been employed (Table 2) to assess the effect of each background variable on the probability of decreasing the incidence of pregnancy related health problem during pregnancy period, controlling other variables. For this analysis, the dependent variable considered is 'experienced with any one pregnancy related health problem (swelling of hand/leg or face; excessive fatigue; convulsion not from fever; nauseas and vomiting; excessive bleeding and abdominal pain; high/low blood pressure), which has been coded as ' 0 ' and not experienced any health problems coded as ' 1 '. It is noted from the logistic regression analysis that the chance of getting any one pregnancy related health problem is consistently improving with the improving socio-economic and demographic conditions of women.

It is observed from (Table 2) that education of women, standard of living condition (SLI), age at marriage and number of ANC visit were statistically significant with the prevalence of pregnancy related health problem among SC population. The age of women, religion, occupation of women, type of family, duration of marital life, age at first birth, birth order, exposure to mass media and distance between health centre and home did not show any kind of statistical association with the dependent variable with the respective reference categories.

It is noted from the (Table 2) logistic regression analysis that when compared with illiterate women, women with higher education were less likely to experience any one pregnancy related health problem $(\mathrm{OR}=$ $0.216)$. It is also noticed that the chance of getting any one pregnancy related health problem was less among the women living in high SLI $(\mathrm{OR}=0.149)$ than the reference category (low SLI). The age at marriage $(\mathrm{OR}=0.208)$ had a significant negative effect on the incidence of any one pregnancy related health problem. It is also observed that when compared with women who made less number of ANC visit, women who made more than six ANC visits were less likely to experience pregnancy related health problem $(\mathrm{OR}=0.214)$.

\section{Treatment Seeking for Health Problems during Pregnancy}

The married young women despite being at risk of experiencing adverse sexual and reproductive health outcomes, are likely or even less likely to seek appropriate pregnancy related care than the older women [12]. Even so, little is known about whether young and adult mothers who experience pregnancy related complications differ in seeking timely and appropriate treatment.

All the women who reported pregnancy related health problems have been asked whether they sought treatment. The proportion of women who sought treatment for different pregnancy related health problems are presented in (Table 3). The result reveals that little above two-third of SC women in the study area sought treatment $(67 \%)$ for any one of the pregnancy related health problems. The result also reveals the proportion of women who sought treatment for different pregnancy related health problems. Comparatively a higher proportion of women who had low/high blood pressure problems had undergone treatment 87.1 and $84.6 \%$ respectively) than the others. It is also noticed that a significant proportion of the women who suffered nauseas and vomiting sought for treatment (73.1\%). Nearly seventy percent of women got medical care for their abdominal pain, excessive bleeding and convulsion problems. Little less than three fifth of women had undergone treatment for their swelling of hand, legs or face problems $(58.8 \%)$. The treatment seeking behavior for the excessive fatigue was quite less $(45.5 \%)$. The study revealed that the prevalence of obstetric morbidity is high in Kerala and Andhra Pradesh among currently married women in South India. The study further showed that treatment seeking behaviour is low in Andhra Pradesh [13]. In Karnataka, one third of the women reported symptoms of reproductive morbidity. Lack of education and low economic status emerged as significant factors 
affecting women's health [14]. A study conducted in Mumbai found that women having a high income and working women are more likely to report reproductive problems than those women who have lower income and those who are not working [15]. Another study further corroborated social barriers such as low self esteem embarrassment or feelings of guilt by the women and perceptions about obstetric morbidity among her relatives which prevent her from seeking health care services [16].

\section{Treatment Seeking Behavior of Women during Pregnancy by Background Characteristics}

The (Table 4) shows the percentage distribution of women who sought treatment for their pregnancy related health problems according to background characteristics. The result indicates that younger women were more likely to receive treatment for health problems during pregnancy $(71.2 \%$ among $18-20$ years) than those aged 24 years $(65.7 \%)$. It is seen from the Chi-square test that the treatment seeking behavior of women was insignificantly associated with the age of women. The women's education had a positive relationship with treatment seeking behavior. In the study area, majority of women who completed higher secondary and above education received treatment for the health problems during pregnancy $(80 \%)$, whereas this proportion for illiterates was only $52 \%$. The analysis shows that the treatment seeking behavior for pregnancy related health problems and the level of women's education had significant association with a Chi-square value of 13.82 at $p=$ .005. The treatment seeking behavior was more pronounced among employed women than their counterparts. Nearly three-fourth of non-agricultural labourers received treatment for their pregnancy related health problems (74.5\%), whereas this proportion for women working in agricultural sector was $67 \%$ and non-working women was $59.7 \%$. The findings indicate that women in households in the highest SLI were more likely to receive treatment for their pregnancy related health problems $(80 \%)$ than women in households in the lowest SLI (55.2\%). The study also reveals that women's standard of living had significant association with the treatment seeking behaviour with a Chi-square value of 21.26 at $p=.000$.

The (Table 4) explains that the relationship between treatment seeking behaviour and age at marriage follows a positive association. The women whose age at first marriage was 22 and above were more likely to receive treatment for their pregnancy related health problems $(80 \%)$ than those aged less than 18 years $(63.7 \%)$. The proportion of women, who sought treatment for health problems during pregnancy decreases sharply by birth order. Birth order had a negative influence on treatment seeking behaviour during pregnancy. The higher birth order pregnancies were less likely to receive treatment during pregnancy $(63.8 \%)$ than the lower birth order pregnancies $(69.3 \%)$. The proportion of women who received treatment for health problems during pregnancy was higher for women who were frequently exposed to mass media (74.6\%) than less frequently exposed to mass media (64.9\%). The Chi-square results also prove the association between women's exposure to media and treatment seeking behaviour with a Chi-square value of 11.86 at $p=.006$. The distance between health care facilities and women's residence shows a significant association with their treatment seeking behaviour. The result explains that women residing within one $\mathrm{Km}$ radius of health care facilities were more likely to receive the treatment for their health problems during pregnancy $(80.3 \%)$ than women residing four $\mathrm{Km}$ away from health care facilities $(62.9 \%)$. It observed that the proportion of women who received the treatment for pregnancy related health problems decreased when the distance between the residence and health care institution increased.

In India the proportion of urban women utilizing the maternal care services is more than two-times as compared to rural women. This is because the urban women are at beneficial position regarding accessibility to the maternal care services. The women of lower castes are less likely to avail of the maternal care services compared with the higher caste women. This is mainly because caste status influences the educational status of women and their attitude about health care provisions. When the influences of other intervening factors are controlled, education emerges as the single most important determinant of maternal health care utilization in India [17]. Educated women with at least middle schooling are nearly eight times as likely to receive antenatal care for their births as illiterate women and literate women with less than middle schooling are more than three times likely. The pattern is similar for utilization of the other maternal care services. Education increases antenatal care awareness and brings about changes in health seeking behaviour for better. It is well known that there is multiplicity of factors influencing utilization of health care services including maternal care services. Multivariate analysis of the data from National Sample Survey in the year 1995-96 displays the importance of mother's knowledge of health production function and physical access to health care services in determining utilization of maternal care services in a population [18].

\section{Conclusion}

In the study area, majority of women were experiences various health problems during pregnancy and in most of the cases they suffer from more than one problem. These problems are usually related to nutritional deficiencies, which result from women's low status in the household along with her poor socio-economic background. The present study indicates that the health-seeking behaviour of women has an important influence on health problems experienced during pregnancy. Therefore, attention should be given to improve the health 
seeking behaviour of women by health workers. But antenatal care coverage alone cannot reduce the plight of pregnant women. The present study emphasis that socio-demographic factors influencing on treatment seeking behaviour of women towards health problems during pregnancy period. Educated mothers are considered to have a greater awareness of the existence of maternal health care services and benefited in using such services and also educated mothers are likely to have better knowledge and information on modern medical treatment. As education empowers women, they have greater confidence and capability to make decision to use modern health care services for themselves and for the children. Education also enables women to take personal responsibility for their own health and the health of their children.

The present study indicates that women in households in the highest SLI were more likely to receive treatment for their pregnancy related health problems than women in households in the lowest SLI. The status of women has to improve so that they are not discriminated against in matters of food. It should be realized that women should not be looked upon only as potential mothers rather she should be given all opportunities to grow up as a healthy child and then develop to a healthy adult. Then only she can become a healthy mother capable to bear a healthy child. This requires change in the attitude of the whole society. The state Government should be strengthening health activities to increase the treatment seeking behaviour towards health problems during pregnancy period among deprived population.

\section{References}

[1]. World Health Organization, Maternal mortality, estimates developed by WHO, UNICEF, UNFPA and World Bank, 2005.

[2]. R. Ramasubban, and S. Jejeebhoy, Women's reproductive health in India, Rawat Publications, New Delhi, 2000.

[3]. A. Chaurasia, Obstetric risk and obstetric care in Central India, Social Change, 36(4), 2006, 48-66.

[4]. International Conference on Population and Development, Cairo, New York, 5-13 September, 1994.

[5]. J. C. Bhatia, and J. Cleland, Self reported symptoms of gynecological morbidity and their treatment in South India, Studies in Family Planning, 26(4), 1995, 203-216.

[6]. Beteille, National Focus Group on Problems of Scheduled Cates and Scheduled Tribe Children, Census, Government of India, Office of the Registrar General and Census Commissioner, 2001.

[7]. Census, Govt of India (Office of the Registrar General and Census Commissioner), 2001.

[8]. Ministry of Health and Family Welfare (MOHFW). Reproductive and Child Health Programme: Schemes for Implementation, Department of Family Welfare, New Delhi, 1997.

[9]. R. Pebley Anne, Noreen Goldman, and German Rodriguez,.Prenatal and Delivery Care and Childhood Immunization in Guetemala: Do Family and Community Matter?. Demography, Vol. 33, No. 2, 1996, pp.231-246.

[10]. Papia Raj, Pregnancy and health -seeking behaviour among married women in Uttar Pradesh, India, Research and Practice in Social Science, Vol.1, 2005, No. 48-63.

[11]. National Family Health Survey-3. (NFHS-3) Ministry of Health and Family Welfare, Government of India, $2007-08$.

[12]. H.W. Reynolds, E.L. Wong, and H. Tucker, Adolescents' use of maternal and child health services in developing countries, International Family Planning Perspectives, 32(1), 2006, 6-16.

[13]. R.S. Reshmi, and U, Sayeed, Reproductive morbidity among currently married women in South India: Evidence from NFHS II, Journal of Family Welfare, 52(2), 2006, 40-58.

[14]. J. C. Bhatia, and J. Cleland, Self reported symptoms of gynecological morbidity and their treatment in South India, Studies in Family Planning, 26(4), 1995, 203-216.

[15]. I. Parikh, V. Taskar, N. Dharap, and V. Mulgaokar, Gynecological morbidity among women in Bombay slums, Streehitakarni, Mumbai, 1980.

[16]. K. Narayan, Issues on obstetric morbidity: Findings from community based research, Paper presented at the Workshop on Reproductive Health In India: New Evidences and Issues, Pune, India, 2000.

[17]. Govindasamy, Pallavi, and B.M. Ramesh, Maternal Education and Utilization of Maternal and Child Health Services in India. National Family Health Survey Subject Reports, 1997, No.5.

[18]. S. Sarma, and H. Rempel, Household decision to utilize maternal and health care in India, World population and Health, February: $1-22,2007$.

Table 1: Distribution of Women by Pregnancy-related Health Problems (Multiple responses)

\begin{tabular}{|l|c|c|}
\hline Pregnancy-related health problems & $\begin{array}{c}\text { Number of } \\
\text { women }\end{array}$ & Percentage \\
\hline Women who had experienced health problem & 352 & 58.2 \\
\hline Nauseas and vomiting & 108 & 30.7 \\
\hline Abdominal pain & 94 & 26.7 \\
\hline Excessive fatigue & 88 & 25.0 \\
\hline Convulsion & 71 & 20.2 \\
\hline Swelling of hand, legs or face & 68 & 19.3 \\
\hline Excessive bleeding & 33 & 9.4 \\
\hline Low blood pressure & 31 & 8.8 \\
\hline High blood pressure & 13 & 3.4 \\
\hline
\end{tabular}


Table 2: Binary Logistic Regression Examining the Effect of Background Characteristics on Health Problems during Pregnancy Period

\begin{tabular}{|c|c|c|c|}
\hline Background characteristics & $\begin{array}{c}\text { Logistic } \\
\text { Coefficient }(\beta)\end{array}$ & $\begin{array}{c}\text { Significant value } \\
\text { (p) }\end{array}$ & $\begin{array}{c}\text { Odds Ratio } \\
\operatorname{Exp}(\beta)\end{array}$ \\
\hline \multicolumn{4}{|l|}{ Age of women } \\
\hline \multicolumn{3}{|l|}{$18-20$ (ref) } & 1.000 \\
\hline $21-23$ & -.369 & .290 & .692 \\
\hline 24 years & -.800 & .114 & .449 \\
\hline \multicolumn{4}{|l|}{ Religion } \\
\hline \multicolumn{3}{|l|}{ Hindu (ref) } & 1.000 \\
\hline Christian & -.491 & .066 & .612 \\
\hline \multicolumn{4}{|l|}{ Education of women } \\
\hline \multicolumn{3}{|l|}{ Illiterates (ref) } & 1.000 \\
\hline Primary education & .417 & .525 & 1.518 \\
\hline Secondary education & -.823 & .118 & .439 \\
\hline Higher secondary and above & -2.712 & .000 & .216 \\
\hline \multicolumn{4}{|l|}{ Occupation of Women } \\
\hline \multicolumn{3}{|l|}{ Non-workers (ref) } & 1.000 \\
\hline Agricultural labourers & -.034 & .812 & .767 \\
\hline Non-agricultural labourers & -.063 & .787 & .665 \\
\hline \multicolumn{4}{|l|}{ Type of family } \\
\hline \multicolumn{3}{|l|}{ Nuclear Family (ref) } & 1.000 \\
\hline Joint family & -.216 & .291 & .805 \\
\hline \multicolumn{4}{|l|}{ Standard of living index } \\
\hline Low level (ref) & & & 1.000 \\
\hline Medium level & -.547 & .016 & .579 \\
\hline High level & -1.902 & .000 & .149 \\
\hline \multicolumn{4}{|l|}{ Age at marriage } \\
\hline \multicolumn{3}{|l|}{18 or less years (ref) } & 1.000 \\
\hline $19-20$ & -.435 & .564 & .647 \\
\hline 21 or more & -.388 & .006 & .208 \\
\hline \multicolumn{4}{|l|}{ Duration of marital life } \\
\hline $1-2$ years (ref) & & & 1.000 \\
\hline $3-4$ years & -.089 & .760 & .915 \\
\hline $5-6$ years & .076 & .884 & 1.079 \\
\hline \multicolumn{4}{|l|}{ Age at first birth } \\
\hline \multicolumn{3}{|l|}{19 or less years (ref) } & 1.000 \\
\hline $20-22$ & .103 & .892 & 1.108 \\
\hline 23 or more & -1.311 & .149 & .270 \\
\hline \multicolumn{4}{|l|}{ Birth order } \\
\hline \multicolumn{3}{|l|}{ First birth (ref) } & 1.000 \\
\hline Second birth & .215 & .458 & 1.240 \\
\hline Third birth & -.205 & .241 & .746 \\
\hline \multicolumn{4}{|l|}{ Exposure to mass media in weekly } \\
\hline \multicolumn{3}{|l|}{ Less frequently (ref) } & 1.000 \\
\hline More frequently & -.243 & .232 & .785 \\
\hline \multicolumn{4}{|l|}{ Distance of health care facility } \\
\hline Within $1 \mathrm{Km}$ (ref) & & & 1.000 \\
\hline $2-3 \mathrm{Km}$ & -.128 & .693 & .879 \\
\hline 4 or more $\mathrm{Km}$ & -.037 & .901 & .963 \\
\hline Number of ANC visits during pregna & & & \\
\hline Less 3 visit (ref) & & & 1.000 \\
\hline $3-5$ visits & -.060 & .056 & .542 \\
\hline 6 or more visits & -.015 & .002 & .214 \\
\hline Constant & 2.613 & .000 & 13.640 \\
\hline
\end{tabular}

$-2 \log$ likelihood $=1312.284$

Table 3: Distribution of Women by Treatment Seeking Behaviour during Pregnancy (Multiple responses)

\begin{tabular}{|l|c|c|c|}
\hline \multicolumn{1}{|c|}{ Health problems during pregnancy } & \multicolumn{2}{c|}{ Treatment seeking behaviour } & \multirow{2}{*}{ Total } \\
\cline { 2 - 4 } & Yes & No & 35.0 \\
\hline Women who sought treatment for health problem & 67.0 & 12.9 & 31 \\
\hline Low Blood pressure & 87.1 & 15.4 & 13 \\
\hline High blood pressure & 84.6 & 26.9 & 108 \\
\hline Nauseas and vomiting & 73.1 & 30.3 & 33 \\
\hline Excessive bleeding & 69.7 & 30.9 & 94 \\
\hline Abdominal pain & 69.1 & 31.0 & 71 \\
\hline Convulsion & 69.0 & 41.2 & 68 \\
\hline Swelling of hand, legs or face & 58.8 & 54.5 & 88 \\
\hline Excessive fatigue & 45.5 & & \\
\hline
\end{tabular}


Table 4: Percentage Distribution of Treatment Seeking Behavior of Women during Pregnancy by Background Characteristics

\begin{tabular}{|c|c|c|c|c|c|}
\hline \multirow{2}{*}{ Background characteristics } & \multicolumn{2}{|c|}{ Treatment seeking behaviour } & \multirow{2}{*}{ Total } & \multirow{2}{*}{$\mathbf{X}^{2}$} & \multirow{2}{*}{$P$} \\
\hline & Yes & No & & & \\
\hline \multicolumn{6}{|l|}{ Age of women } \\
\hline $18-20$ & 71.2 & 28.8 & 67 & \multirow{3}{*}{.734} & \multirow{3}{*}{.693} \\
\hline $21-23$ & 66.0 & 34.0 & 212 & & \\
\hline 24 years & 65.7 & 34.3 & 73 & & \\
\hline \multicolumn{6}{|l|}{ Education of women } \\
\hline Illiterate & 51.9 & 48.1 & 27 & \multirow{4}{*}{13.82} & \multirow{4}{*}{.005} \\
\hline Primary education & 61.2 & 38.8 & 49 & & \\
\hline Secondary education & 69.4 & 30.6 & 271 & & \\
\hline Higher secondary and above & 80.0 & 20.0 & 5 & & \\
\hline \multicolumn{6}{|l|}{ Occupation of women } \\
\hline Non-workers & 59.7 & 40.3 & 51 & \multirow{3}{*}{13.01} & \multirow{3}{*}{.006} \\
\hline Agricultural labourers & 67.0 & 33.0 & 218 & & \\
\hline Non -agricultural labourers & 74.5 & 25.5 & 83 & & \\
\hline \multicolumn{6}{|l|}{ Standard of living index } \\
\hline Low & 55.2 & 44.8 & 172 & \multirow{3}{*}{21.26} & \multirow{3}{*}{.000} \\
\hline Medium & 78.2 & 21.8 & 170 & & \\
\hline High & 80.0 & 20.0 & 10 & & \\
\hline \multicolumn{6}{|l|}{ Age at marriage } \\
\hline Less than 18 years & 63.7 & 36.3 & 18 & \multirow{4}{*}{3.21} & \multirow{4}{*}{.361} \\
\hline 18-19 years & 72.8 & 27.2 & 112 & & \\
\hline 20-21 years & 73.9 & 26.1 & 117 & & \\
\hline $22-23$ years & 80.0 & 20.0 & 5 & & \\
\hline \multicolumn{6}{|l|}{ Birth order } \\
\hline First & 69.3 & 30.7 & 202 & \multirow{3}{*}{3.12} & \multirow{3}{*}{.573} \\
\hline Second & 65.2 & 34.8 & 127 & & \\
\hline Third & 63.8 & 36.2 & 23 & & \\
\hline \multicolumn{6}{|l|}{ Exposure to mass media in weekly } \\
\hline More frequently & 74.6 & 25.4 & 114 & \multirow[t]{2}{*}{11.86} & \multirow[t]{2}{*}{.006} \\
\hline Less frequently & 64.9 & 35.1 & 238 & & \\
\hline \multicolumn{6}{|l|}{ Health care facility } \\
\hline Within one Km & 80.3 & 19.7 & 45 & \multirow{3}{*}{13.42} & \\
\hline $2-3 \mathrm{Km}$ & 66.7 & 33.3 & 97 & & .007 \\
\hline 4 or more $\mathrm{Km}$ & 62.9 & 37.1 & 210 & & \\
\hline Total & 67.0 & 33.0 & 352 & & \\
\hline
\end{tabular}

